INNOVACIÓN

\title{
Formación por competencias y prácticas pedagógicas: Reflexiones en torno al rediseño curricular de la carrera de Derecho de la Universidad de Atacama
}

\author{
Formação por competências e prática pedagógicas: Reflexões ao redor \\ do redesenho curricular do curos de Direito da Universidade de Atacama \\ Competence-based training and pedagogical practices: Reflections \\ on the curriculum redesign model of the Law career at Atacama University
}

\author{
Tomás Eduardo Garay Pérez \\ Universidad de Atacama, Chile
}

\begin{abstract}
RESUMEN Este artículo analiza el rediseño curricular que ha experimentado la carrera de Derecho de la Universidad de Atacama, proceso en el cual se ha incorporado el paradigma de la formación por competencias en la conformación de su plan de estudios. Examinamos los desafíos pedagógicos que implica la aceptación de este enfoque, en cuanto oportunidad para revisar y actualizar la metodología usualmente utilizada para la enseñanza-aprendizaje del derecho. Buscamos determinar si la formación basada en competencias tiene como única finalidad la preparación de un profesional calificado para responder a las exigencias del mercado laboral por sobre una dimensión intelectual, que comprenda, además, el desarrollo de saberes y bagaje jurídicos.
\end{abstract}

PALABRAS CLAVE Competencias, formación por competencias, prácticas pedagógicas, educación legal.

RESUMO Este artigo analisa o redesenho curricular alterado pela Faculdade de Direito da Universidade do Atacama (UDA), processo em que o paradigma da formação baseada em competências foi incorporado à formação de seu currículo. Para este fim, os desafios pedagógicos envolvidos na aceitação desta abordagem serão examinados, como uma oportunidade para rever e atualizar a metodologia normalmente usada para ensino e aprendizagem de direito e, finalmente, para determinar se a formação baseada em competência é apenas para fins de a preparação de um profissional qualificado para 
responder às demandas do mercado de trabalho sobre uma dimensão intelectual que inclui, para além, o desenvolvimento do conhecimento e formação jurídica.

PALAVRAS-CHAVE Competências, formaçãopor competências, prática pedagógicas, educação jurídica

\begin{abstract}
The present article analyzes the curriculum redesign that law career has been undergone at Atacama University, it is a process in which has been involved a paradigm of the formation by competences in its learning plan. For this reason, the pedagogical challenges involved in the acceptance of this approach will be studied and the methodology usually used in the teaching-learning process of law will be also revised and updated. Finally, it is going to be determined if the training based on competence has as the only purpose to train a qualified professional to respond to the demands of the labor market by over an intellectual dimension that in addition, it includes the development of legal knowledge and background.
\end{abstract}

KEYWORDS Competences, competences-based training, pedagogical practices, legal education.

\title{
Introducción
}

Durante los últimos años, la formación por competencias se ha instalado como el nuevo paradigma (Cardozo-Brum, 1989; Gutiérrez-Barba y Valderrábano-Almegua, 2017; Díaz-Posada, Varela-Londoño y Rodríguez-Burgos, 2017; Alvarado-Herrera, González-Sandoval y Paniagua-Cortés, 2018; Ganga, Smith, Fossatti y Leyva, 2017) respecto del cual se están configurando los proyectos educativos de distintas casas de estudios superiores chilenas. La Universidad de Atacama (UDA) no ha sido la excepción. Ya en el año 2006 declaraba en su Plan de Desarrollo Estratégico que uno de los objetivos dirigidos a lograr la misión institucional era el de «formar profesionales con competencias para el mundo del trabajo y la sociedad del conocimiento» (UDA, 2006: 34). Para ello, resultaba necesario el rediseño curricular de los programas de estudios de las carreras que imparte, con el objeto de que estos nuevos planes curriculares se ajustasen a la formación con enfoque en competencias.

Producto de lo anterior, durante el año 2011 - en el marco de la ejecución del proyecto Mecesup ATA 0706 ANF titulado «Rediseñar el plan de estudios de la Licenciatura en Ciencias Jurídicas de las Universidades de Atacama y Antofagasta»- se implementó una nueva malla curricular para la carrera de Derecho, plan de estudios que rescató elementos del enfoque por competencias, y se avanzó significativamente en la finalidad de darle coherencia al plan de formación del estudiantado con el perfil de egreso declarado por la UDA. 
Ahora bien, el hecho de que la formación por competencias sea el enfoque en boga y en razón del cual se estén reconfigurando planes y programas de estudios, para los actores educativos que se han visto involucrados en este proceso exige una serie de desafíos, que van desde la comprensión de aspectos conceptuales hasta la reformulación de prácticas pedagógicas. Ello puesto que, tal como advierte Díaz Barriga (2006: 8), siempre está latente la posibilidad de una aplicación superficial de este enfoque, consecuencia de la negativa generalizada de atender a la problemática conceptual que subyace en el concepto de competencias, lo que podría generar orientaciones apresuradas insuficientes para provocar el cambio esperado o con nulo impacto en las prácticas educativas.

Con todo, cabe aclarar que escapa a los fines del presente trabajo el profundizar en el ethos de esta institución. Es un tema no resuelto que suma tanto detractores como opositores. Pero ello no obsta a que, desde una mirada crítica y analítica, sean relevadas las implicancias que ha traído aparejada la incorporación del enfoque por competencias en el proceso formativo de los futuros profesionales del derecho de la UDA, cubriendo el análisis tanto de aspectos coyunturales como curriculares y metodológicos.

Para ello, en primer lugar serán abordadas algunas cuestiones conceptuales y de contexto para, de este modo, tener nociones generales que permitan comprender qué implica la formación por competencias y cuál o cuáles fueron los sucesos que impulsaron su consolidación como nuevo enfoque para el diseño de los proyectos educativos. A continuación, se analizará el proceso de incorporación de este enfoque en el rediseño curricular (Gil, 2018) del programa de estudios de la carrera de Derecho de la UDA y los desafíos que implica desde la perspectiva de la práctica docente, formulando algunas bases teóricas acerca del rol que desempeña (o debe desempeñar) el docente en el proceso enseñanza-aprendizaje, desde una mirada crítica al modelo tradicional usualmente utilizado en la docencia del derecho.

Por último, serán tratadas algunas ideas relativas a las finalidades que persigue la educación en competencias y los límites (o la falta de ellos) con las visiones pedagógicas pragmáticas que ven la preparación del estudiante para su inserción en el mundo laboral como el fin principal (y probablemente único) de la educación.

\section{Generalidades acerca de la formación por competencias}

Indica Sergio Tobón (2006: 2) que el concepto de competencia tiene múltiples definiciones al confluir en él variados aportes disciplinares, además de diversas tendencias sociales y económicas. Desde un punto de vista histórico, para Tobón ya en la filosofía griega puede encontrarse un escenario ideal para la construcción del enfoque por competencias. $\mathrm{Al}$ respecto, señala: 
En primer lugar, la reflexión filosófica está medida por un modo de pensar problémico donde se interroga el saber y la realidad. Encontramos cómo los temas esenciales son abordados por los filósofos griegos desde problemas contextualizados, y en este sentido, no son ocurrencias al azar; por el contrario, son propuestas para interrogar la realidad, el ser y el hombre de una forma fundamentada. En el concepto actual de competencias, la interrogación de la realidad ocupa un papel central en tanto se tiene como base la resolución de problemas con sentido para las personas.

En segundo lugar, la filosofía griega realiza construcciones buscando aprehender la realidad en sus conceptos, estableciendo relaciones y conexiones entre los diferentes temas y problemas. Esto hace que las elaboraciones filosóficas posean hilos y tejidos conductores, trascendiendo así la mera casualidad. Actualmente, en la formación de competencias se insiste en la necesidad de articular los saberes de distintas disciplinas (Tobón, 2005: 23).

Sin embargo, la literatura especializada (Díaz Barriga, 2006; Tobón, 2005; Galdeano-Bienzobas y Valiente Barderas, 2009) afirma que, en materia de educación, se le atribuye a Chomsky la utilización por primera vez del concepto de competencia, a propósito de su teoría de la gramática generativa transformacional. Chomsky en el año 1964 elabora la idea de la competencia lingüística, «la cual da cuenta de la manera cómo los seres humanos se apropian del lenguaje y lo emplean para comunicarse» (Tobón, 2005: 25).

A partir de entonces, dicha expresión comenzó a utilizarse en diversas áreas, como en el caso de las competencias ideológicas, competencias comunicativas, competencias enciclopédicas, etcétera (Díaz Barriga, 2006).

En paralelo, la idea de competencia comienza a utilizarse también en el mundo del trabajo. En tal sentido, Díaz Barriga indica:

Se le concibe como una estrategia que se apoya fundamentalmente en el análisis de tareas, a partir de la cual se busca determinar las etapas puntuales en las que se debe formar a un técnico medio, por ejemplo un mecánico automotriz, un tornero, en la adquisición de las habilidades y destrezas que le permitan un desempeño eficiente en su labor (Díaz Barriga, 2006: 13).

Así, el uso del vocablo competencia, tanto en su faceta lingüística como en lo relacionado con lo laboral, fueron configurando el sentido con el que se comenzaría a utilizar en educación.

Pero esta brevísima contextualización resulta incompleta mientras no se haga alusión al suceso que permitió que el enfoque por competencias dejara de ser una abstracción, un objeto de discusión para teóricos de la educación, para convertirse en una acción concreta, que dotó de contenidos y directrices a múltiples sistemas educativos: el proceso de Bolonia. 
Su hito fundacional se sitúa en la firma de la Declaración de Bolonia de 1999, por la cual los ministros de Educación europeos manifestaron la voluntad de sus países de crear un espacio común en materia de educación superior, que derivó en la creación del Espacio Europeo de Educación Superior (EEES). Entre los objetivos de este proceso se encuentran el adecuar la universidad a los desafíos que presenta una sociedad globalizada, considerando, además, los avances en materia tecnológica que ha experimentado la humanidad en las últimas décadas, como asimismo la adecuación de los currículos con el objeto de homogenizar los planes de estudios de las distintas casas de estudios europeas y así permitir el intercambio de conocimientos, estudiantes y docentes, procurando garantizar al máximo la calidad de la educación (Montero Curiel, 2010).

Resultado de la Declaración fue la implementación por parte de diversas universidades europeas del proyecto "Tuning Educational Structures in Europe» - denominado habitualmente Proyecto Tuning (Beneitone y otros, 2007: 109) -, por el que se buscó concretar en la práctica los objetivos declarados en Bolonia. Este proyecto entrega una definición de lo que debe entenderse por competencia en el contexto de la educación superior, indicando: «Las competencias representan una combinación de atributos (con respecto al conocimiento y sus aplicaciones, aptitudes, destrezas y responsabilidades) que describen el nivel o grado de suficiencia con que una persona es capaz de desempeñarlos» (González y Wagenaar, 2003: 80).

A propósito de dicha definición, Goñi y Meseguer (2010) precisan que las competencias son referencias sobre las cuales se estructurarán los nuevos planes de estudio de grado y posgrado.

De todo lo anterior, podemos indicar que Tobón nos entrega una de las definiciones de competencia que, probablemente, abarque la mayor cantidad de elementos de contexto y análisis:

[Son] procesos complejos que las personas ponen en acción-actuación-creación, para resolver problemas y realizar actividades (de la vida cotidiana y del contexto laboral-profesional), aportando a la construcción y transformación de la realidad, para lo cual integran el saber ser (automotivación, iniciativa y trabajo colaborativo con otros), el saber conocer (observar, explicar, comprender y analizar) y el saber hacer (desempeño basado en procedimientos y estrategias), teniendo en cuenta los requerimientos específicos del entorno, las necesidades personales y los procesos de incertidumbre, con autonomía intelectual, conciencia crítica, creatividad y espíritu de reto, asumiendo las consecuencias de los actos y buscando el bienestar humano (Tobón, 2005: 49).

Ahora, atendiendo que el objeto de estudio de este artículo será la incorporación de este enfoque en el ámbito del derecho, comprenderemos que competencia «es una capacidad que se adquiere a partir de un conjunto de conocimientos, habilidades y 
actitudes (aprendizaje significativo), y que es transferida a múltiples contextos de manera consciente...» (Sanromán Aranda y Morales Vega, 2016: 189).

Si las competencias son desarrolladas por los estudiantes de derecho, actuarán como verdaderos juristas dentro del entorno social en que ejercen su profesión, junto con enriquecer la realidad científica a través de sus prácticas profesionales y el estudio del fenómeno jurídico (Rivera Ayala, 2015: 4).

\section{Rediseño curricular de la carrera de Derecho en la UDA: transitando hacia la formación por competencias}

En el transcurso del año 2006, la carrera de Derecho de la UDA fue sometida voluntariamente al proceso de acreditación, obteniendo dicha calidad por el plazo de dos años. La Comisión Nacional de Acreditación (CNA) detectó, entre otras debilidades, que en cuanto a su malla curricular «la experiencia de aplicación del plan de estudios vigente a la fecha mostró que las condiciones de operación de la carrera no permitían ajustarse a una concepción de aprendizaje autónomo y crítico, tarea relevante y aún pendiente» (CNA, 2006: 3), sin perjuicio de que la unidad estuviera trabajando en la reformulación del plan curricular. En el año 2010, al someterse nuevamente en forma voluntaria al proceso de acreditación, obtuvo, en segunda instancia, la acreditación por solo dos años (2011-2013), y reiteraron las observaciones ya efectuadas respecto de su plan de estudios, no obstante que rescatara en su acta de acuerdo las nacientes iniciativas para la formación en competencias transversales que, en lo futuro, sería positivo profundizar (CNA, 2011).

Lo indicado por la Comisión Nacional de Acreditación en este segundo proceso de acreditación no resulta baladí, puesto que el año 2011 fue implementada una nueva malla curricular que, a diferencia de la que se mantuvo vigente hasta el año 2010, basa su configuración en el paradigma de la formación del estudiante con base en el desarrollo de sus competencias, adaptando el perfil de egreso al nuevo plan de estudios. Al respecto, la Agencia Acreditadora Qualitas, encargada en esta oportunidad de llevar a cabo el proceso, destacó, a diferencia de lo que había ocurrido anteriormente, la reformulación del plan de estudios basada en una matriz de tributación de las competencias generales y específicas establecidas en el plan de estudios, lo que permite evidenciar la consistencia y coherencia entre el perfil de egreso y el plan de estudios (Qualitas, 2006: 4). En esta ocasión se acreditó la carrera en segunda instancia y por el plazo de cuatro años (2016-2020).

En atención a ello, cabe precisar que en el proceso de reforma curricular el perfil de egreso cobra especial importancia debido a que, tal como lo indican Palomo Vélez y Riveros Ferrada (2015: 58), en un modelo basado en competencias «el perfil profesional constituye una descripción del conjunto de atributos de un licenciado en términos del ejercicio de una profesión, pudiendo ser descrito por las competencias 
asociadas a las prácticas de la misma». En consecuencia, conforme al perfil definido por la UDA, se espera que el egresado de la carrera de Derecho presente las siguientes cualidades:

- Conoce y comprende los conceptos dogmáticos y categorías fundamentales de las ciencias jurídicas.

- Tiene un conocimiento sistemático de los principios generales e instituciones esenciales del ordenamiento jurídico, considerando dentro de sus principales ramas al Derecho Civil, al Derecho Constitucional, al Derecho Penal y al Derecho Procesal.

- Tiene conocimientos y criterios básicos en el área de las ciencias sociales y las humanidades que le permiten una comprensión del derecho y su trascendencia social, así como del ejercicio de las diversas profesiones jurídicas.

- Posee habilidad para expresarse en forma oral y escrita con dominio del lenguaje jurídico.

- Posee habilidad para argumentar y razonar jurídicamente.

- Es capaz de analizar y resolver situaciones jurídicas con un adecuado manejo de las fuentes, identificando los hechos relevantes, las normas y principios aplicables, dando una solución al problema planteado.

- Es capaz de abordar conflictos jurídicos, empleando equilibradamente e indistintamente instituciones públicas y privadas.

- Conoce y comprende la influencia de las instituciones jurídicas en el desarrollo regional y local.

- Es capaz de discernir y hacer valoraciones éticas con relación a normas o situaciones específicas y frente a posiciones o soluciones jurídicas.

Definido el perfil de egreso, el nuevo currículo debió orientarse hacia él dado que, tal como lo indican Zuvanich Hirmas y Donetch Ulloa (2016: 364), a propósito de un proceso similar que llevó a cabo la carrera de Derecho de la Universidad de Magallanes, el perfil constituye el marco de referencia sobre el cual debe organizarse el proceso formativo. Por consiguiente, el nuevo plan de estudios de Derecho de la UDA incorporó asignaturas vinculadas tanto con la formación jurídica general como la formación jurídica específica, estableciendo como matriz de competencias generales que espera que desarrollen sus estudiantes la siguiente:

- Razonar y argumentar jurídicamente conociendo las distintas fuentes del derecho, identificando hechos relevantes, las normas y principios aplicables para elaborar soluciones jurídicas. 
- Desempeñar su actividad profesional en equipos de trabajo como experto en derecho contribuyendo de manera efectiva a sus tareas.

- Comprender los elementos centrales del contexto regional en los que debe desempeñar su actividad profesional.

- Facilitar a las personas su acceso a la justicia, identificando la información relevante que sirvan para orientar soluciones jurídicas convenientes al problema planteado.

- Litigar en los tribunales ordinarios y especiales de justicia sobre la base de estrategias y fundamentos sustentados en sólidos conocimientos del sistema judicial.

- Desempeñar su actividad profesional de manera responsable, de acuerdo a altos estándares éticos.

- Construir textos y discursos jurídicos, empleando un adecuado lenguaje técnico.

En definitiva, la UDA asumió el reto de adecuar el diseño curricular (Pérez-Ruiz, 2018; Hernández-Chacón, 2017; Mesquita, Flores y Lima, 2018; Salas Perea, 2016; Jiménez, Martelo y Jaimes, 2017; Sleeter, 2018) de la carrera de Derecho con base en los desafíos que presenta incorporar los planteamientos formulados por el Informe Tuning para Latinoamérica (Beneitone y otros, 2007: 109), en general, y la Comisión Nacional de Acreditación, en particular, en cuanto a ofrecer una formación basada en el desarrollo de competencias, aun cuando los resultados de dicha implementación deberán evaluarse una vez que las primeras generaciones de licenciados en Ciencias Jurídicas formados bajo el nuevo modelo se incorporen profesionalmente al mundo laboral, debiendo plantearse un rediseño, de ser necesario, a partir del grado de cumplimiento de las competencias que pretenden desarrollarse en el proceso formativo en contraste con el desempeño de sus profesionales.

Sin embargo, más allá del paso cualitativo que se ha dado en la actualización del currículum y su adecuación a los desafíos que presenta la práctica del derecho en el siglo XXI (la tendencia a la oralidad por sobre la escrituración en los procedimientos judiciales, la apertura de nuevos campos laborales para los operadores jurídicos, los adelantos tecnológicos, la globalización, etcétera), resulta necesario analizar críticamente la forma en que se relaciona la diada que constituye el alma del proceso de enseñanza-aprendizaje del derecho: docente y estudiante. 


\section{Breve repaso a los métodos utilizados en el proceso de enseñanza-aprendizaje en la carrera de Derecho}

Se indicó ya que el rediseño curricular de la carrera de Derecho de la UDA obedece a la necesidad de adecuar su plan de estudios a los desafíos que presenta la educación en el siglo XXI. En este contexto, la formación por competencias es vista «como una fórmula para mejorar el aprendizaje del estudiante, acercando la brecha existente entre la educación universitaria y la práctica profesional» (Pinto Sarmiento, 2014: 70), y que busca incidir significativamente en la forma en que son adquiridos los conocimientos (Sanromán Aranda y Morales Vega, 2016).

En tal orden de ideas, la incorporación de esta nueva visión de cómo comprender la enseñanza de las ciencias jurídicas no ha estado exenta de vicisitudes, si se considera, sobre todo, que aquellos que ejercemos la labor docente en esta área no tenemos (habitualmente) una formación pedagógica previa y que, por circunstancias de la vida, de desarrollo profesional o por vocación, hemos asumido el desafío de participar en el proceso de formación del futuro profesional del derecho.

Ahora bien, hay que tener claro que la formación por competencias no constituye en sí misma un modelo pedagógico, sino un enfoque para la educación (Aedo Barrena, 2014; Tobón, 2006). Por lo tanto, resultaría del todo erróneo pensar que al asumir una casa de estudios el modelo de formación por competencias, necesariamente deben implementarse determinados métodos para aplicarlos en el proceso enseñanzaaprendizaje del derecho. Ello no obsta a que se haga una evaluación respecto de los métodos de enseñanza utilizados mayoritaria y tradicionalmente para, de este modo, concluir si guardan o no coherencia con este nuevo paradigma educativo.

En tal sentido, puede observarse que el método utilizado mayoritariamente sigue siendo el de clase magistral (Elgueta y Palma, 2014), que se centra en la figura del docente que transmite una gran cantidad de información a los estudiantes, quienes luego replicarán dichos contenidos en el momento de la respectiva evaluación. Patricio Lazo realiza una descripción de este método de enseñanza:

Una observación rápida nos indica que en un porcentaje significativo de lecciones o clases de derecho, la dinámica puede ser descrita como sigue: un docente desarrolla ante sus alumnos un discurso sobre la materia en tanto que los discentes se limitan a tomar apuntes. En ocasiones, el profesor hace preguntas a sus alumnos y comprueba hasta qué punto estos retienen lo que se ha dicho y en qué medida son capaces de razonar en cuanto a lo enseñado. Las evaluaciones, conforme este patrón de enseñanza, evalúan la medida en que el alumno reproduce el conocimiento, a la vez que razona sobre él (Lazo González, 2011: 254).

Debe tenerse claro que la situación antes descrita no solo está presente en la enseñanza del Derecho en la UDA y en Chile. El Informe Tuning para América Latina in- 
dica que «la dogmática jurídica ha sido la matriz teórica dominante en la mayor parte de las facultades o cursos, con énfasis metodológico en la transmisión de contenidos teóricos por parte del docente y la absorción de éstos por el estudiante» (Beneitone y otros, 2007: 109).

No obstante, debe considerarse que, aun cuando el método de clase magistral sea el usualmente utilizado en la enseñanza del derecho, sería faltar a la verdad si se indicara que es el único, puesto que, tal como señala Lazo González (2011: 254), puede observarse que en la práctica de los docentes de derecho son utilizadas otras técnicas, como la discusión de textos leídos previo a la respectiva clase, disertaciones realizadas por los alumnos, trabajos de investigación, simulaciones de juicios, etcétera.

Por tanto, que la enseñanza del derecho siga impartiéndose bajo el método tradicional, no resulta coherente con la incorporación de la formación por competencias en el currículum de derecho, dado que aquella práctica pedagógica no permite desarrollar la reflexión del estudiante - como se verá más adelante-, pues se limita a la mera repetición de contenidos, mientras que en el enfoque por competencias, el estudiante debe descubrir por sí mismo los conocimientos mediante el desarrollo de sus destrezas y habilidades, lo que solo se logrará si el docente abandona su rol de reproductor para dar paso a un pedagogo facilitador (Sanromán Aranda y Morales Vega, 2016: 190).

\section{De la enseñanza centrada en el docente a la construcción del aprendizaje por el educador y estudiante: reflexiones y crítica}

Rodríguez-Sosa y Solís-Manrique (2017) indican que existe una serie de creencias presentes en el desarrollo de la docencia, sostenidas como verdades personales y derivadas de las percepciones que surgen desde las experiencias. Un de estas es la que señala que, en el campo de la educación superior, los procesos enseñanza-aprendizaje deben girar en torno a los docentes, y los estudiantes deben asumir un mero rol receptivo. En este punto, resulta interesante hacer una pequeña revisión a la crítica efectuada por Paulo Freire a este método de enseñanza que denomina educación bancaria, y a los objetivos que, a su juicio, persigue su reproducción. Indica Freire:

Referirse a la realidad como algo detenido, estático, dividido y bien configurado o en su defecto hablar o disertar sobre algo completamente ajeno a la experiencia existencial de los educandos deviene, realmente, la suprema inquietud de esta educación. Su ansia irrefrenable. En ella, el educador aparece como su agente indiscutible, como su sujeto real, cuya tarea indeclinable es «llenar» a los educandos con los contenidos de su narración. Contenidos que solo son retazos de la realidad, desvinculados de la totalidad en que se engendran y en cuyo contexto adquieren sentido. En estas disertaciones, la palabra se vacía de la dimensión concreta que debería poseer y 
se transforma en una palabra hueca, en verbalismo alienado y alienante. De ahí que sea más sonido que significado y, como tal, sería mejor no decirla (Freire, 2012: 71).

Según Freire, la educación disertadora «es la sonoridad de la palabra y no su fuerza transformadora», y conduce la narración del sujeto a la memorización mecánica, por parte de los estudiantes, del contenido narrado, transformándolos en meros recipientes que deben ser llenados por el docente, considerándose mejor educador a aquel que logre llenar con la mayor cantidad de información al alumno-recipiente. A tal concepción de la educación la denomina bancaria, puesto que «el único margen de acción que se ofrece a los educandos es el de recibir los depósitos, guardarlos y archivarlos. Margen que sólo les permite ser coleccionistas o fichadores de cosas que archivan» (Freire, 2012: 72).

La educación bancaria sería el reflejo de la sociedad opresora, alienante, reproductora de la ignorancia, contraponiéndose a ella la pedagogía liberadora, conciliadora, que busca superar la contradicción educador-educando con el objetivo que ambos se hagan, al mismo tiempo, educadores y educandos (Freire, 2012: 72-84).

Lo planteado por Freire no resulta ajeno a la realidad de la carrera de Derecho en la UDA. Más allá del esfuerzo que han realizado la mayoría de quienes tratan de contribuir a la labor docente en dicha casa de estudio por incorporar nuevos métodos que superen la reproducción de la lección basada en la disertación de contenidos, sigue siendo una práctica constante la de recurrir al método de la clase magistral.

Tal método, desde el punto de vista de las teorías del aprendizaje, puede enmarcarse dentro del conductismo. Los teóricos de esta corriente, indica Doris Gudiño,

definen al aprendizaje como la suma de un cúmulo de conductas aprendidas a través de la práctica y del constante reforzamiento de patrones y de conductas deseadas con lo cual se explica la concepción del aprendizaje como un hecho observable, medible y cuantificable (2011: 300).

Taeli Gómez Francisco señala que el aprendizaje del Derecho desde una mirada conductista implica que:

La conducta que repita, la mayor cantidad de normas jurídicas y algunos que otros contenidos, puede acercarse mejor al conocimiento, por la asociación que ahí se produce. En otros términos, el alumno deberá recibir el objeto desconocido que le está fuera -el qué- y en el ejercicio de su profesión, entregará a los Tribunales de Justicia (Gómez Francisco, 2014: 63-64).

De este modo, para avanzar en nuevas formas de entender y asumir la enseñanza del derecho, en vías de formar a un futuro profesional con capacidad de generar un razonamiento jurídico crítico que vaya más allá de la mera repetición de normas y contenidos teórico sin mayor capacidad de análisis, debe necesariamente transitarse 
hacia un modelo que rescate los aportes de la teoría constructivista, en el cual tanto educador como educando sean constructores del aprendizaje.

Ahora bien, en esta nueva visión acerca de cómo enfrentar el proceso de enseñanza de las ciencias jurídicas que, de acuerdo con todo lo antes señalado, debe orientarse a abandonar el modelo conductista de la clase magistral, juega un papel relevante el educando. Rescatando aspectos de la teoría de la pedagogía liberadora de Freire, bajo el nuevo paradigma el estudiante debe dejar de ser un mero recipiente que se llena de los antecedentes entregados a partir de la narrativa del docente, para pasar a ser un copartícipe activo del aprendizaje.

Este es un tema no menor. El actual perfil de egreso del estudiante de derecho de la UDA indica que la Facultad de Ciencias Jurídicas y Sociales ha declarado competencia sello de sus carreras «el pensamiento crítico y complejo», entendido como:

teoría y práctica formativa, que busca desarrollar y potenciar destrezas cognitivas y sistémicas, que incluyan la capacidad para pensar de manera autónoma, creativa e interconectada, frente a cualquier problema o incertidumbre que le depare el contexto socio-profesional; con una conciencia crítica y actitud transformadora e innovadora, destacando por su compromiso integral hacia una sociedad solidaria y un medio ambiente sano; como asimismo por el respeto a las generaciones futuras (UDA, 2018).

Por lo tanto, ¿de qué modo la educación bancaria aporta al desarrollo del pensamiento crítico y complejo del alumno? ¿Se comprende cabalmente lo que implica la formación por competencias del estudiante de derecho? ¿El pensamiento crítico y complejo podrá desarrollarse si cada vez se le da menos cabida a los ramos de formación general en el primer ciclo del plan de estudios? ¿Existe conocimiento real acerca de qué comprende el pensamiento crítico y complejo?

No pretendemos encontrar respuestas en este trabajo; por el contrario, la propuesta es que, a partir de dichas interrogantes, se inicie la necesaria autocrítica, discusión y reflexión. Sin embargo, vale destacar los esfuerzos que se han hecho desde la misma casa de estudios para cuestionar los métodos tradicionales de enseñanza del derecho. En tal sentido, Taeli Gómez Francisco (2014) ha analizado la relación que existe entre la forma de realizar tal actividad y la realidad social que rodea esa enseñanza, abordando el cómo se ha llevado a cabo la tríada didáctica qué, cómo y para qué enseñar en las universidades chilenas, en cuanto unidad indivisible e inseparable con contextos y contradicciones.

Taeli Gómez Francisco indica que hay dos tipos de crisis que coexisten. La primera se da a nivel de la relación interna de las tramas que componen este objeto de estudio único compuesto por el qué, cómo y para qué enseñar derecho. $\mathrm{O}$ bien, entre ellas hay una relación contradictoria, de presión, desgaste con tendencia reveladora. Y que una mejoría o remedial implicaría una reforma y consolidación de esta forma 
de control social. Es decir, con un sentido más bien táctico de presentar un mejor control social, a las exigencias del mercado (Gómez Francisco, 2014: 61).

La segunda crisis:

expresa nuestra motivación estratégica. Es decir, más allá de intentar ajustar la afinación interna entre estas dimensiones - qué, cómo y para qué enseñar derecho-, busca presentar la crisis como unidad que requiere ser develada como poder y que debe ser transformada, revolucionada, por los requerimientos de la crisis ecosocial (Gómez Francisco, 2014: 61).

En cuanto al qué enseñar, indica:

Ha sido reducido a una fotografía capturada como ley, códigos, o normas jurídicas; una ontologidad corpuscular y no ondulatoria a la vez. Negadora permanente de los cambios, relaciones, redes, realidad. Nuestro qué enseñar, se ha transformado en una cosificación petrificada funcional a una cultura vigilante de paradigmas atávicos. Esto genera incoherencia a la trilogía presionada por un mundo dinámico y complejo. Da fundamentación a la ineficacia del derecho; además, muestra la tozudez de una inmutable e inflexible comunidad jurídica, que recluta a operadores novatos desde primer año, convirtiéndolos como su primera línea de resguardado a esta cultura jurídica (Gómez Francisco, 2014: 63).

En lo relativo a cómo enseñar el qué, indica Gómez que concebido el derecho como algo inmóvil, sin movimiento, una fotografía:

se asevera la existencia de una realidad objetiva distinta del sujeto, que genera la obligación de acercarse a él para conocerlo. Hablamos entonces, de un profesor de derecho, que le entrega y transfiere - el qué, el derecho- a sus estudiantes o les muestra el camino de cómo hacerlo. La enseñanza cumple un rol de recipiente o medio de transporte de algo jurídico acabado (Gómez Francisco, 2014: 63).

Dicha afirmación coincide con el cuestionamiento realizado por Freire: el estudiante de derecho se transforma en un recipiente que es llenado de contenidos ( $i \mathrm{CO}$ nocimientos?), que luego son replicados por el receptor al momento de efectuarse la respectiva evaluación. El para qué enseñar devuelve, según la autora, a los dos tipos de crisis antes mencionados: o se alinea esta trilogía poniéndola al servicio del mercado que demanda buenos especialistas en el contexto de un mundo global complejo y dinámico, o al requerimiento de motivación estratégica dadas las necesidades que presenta una crisis ecosocial (Gómez Francisco, 2014: 67-68).

Concluye, a modo de reflexión final, que no busca entregar respuestas a las interrogantes que surgen a propósito de la educación del dserecho, puesto que no pueden entregarse ideas o argumentos lineales o reduccionistas (el derecho es dinámico per se), sin perjuicio de pensarse la enseñanza liberadora del derecho teniéndose pre- 
sente siempre que el derecho es control social y, por consiguiente, lo es también su educación (Gómez Francisco, 2014: 69).

En definitiva, en la medida que tengamos la capacidad de entender la triada qué, cómo y para qué, podremos distinguir la función estática, reduccionista, unidimensional y legitimadora que cumple el derecho, de aquella función crítica que «devela las relaciones de poder, nada contracorriente produciendo igualdad allí donde reina la discriminación, instituye sujetos de Derecho donde había seres que esperaban beneficencia» (Cardinaux y Palombo, 2007: 133).

\section{Pedagogía pragmática y su influencia en la conformación de planes y programas de estudios. ¿Riesgos de la formación por competencias?}

Se indicó en el apartado anterior que el ejercicio de la docencia del derecho debe comprenderse a partir de la relación que existe entre el desarrollo de tal actividad y la realidad social que rodea esa enseñanza. Por tanto, cobra importancia la finalidad que persigue su enseñanza: o se busca, por una parte, la formación de buenos especialistas al servicio de las demandas del mercado laboral, o, por el contrario, sus fines serán la búsqueda de respuestas a las necesidades que presenta la crisis social que se vive en un momento dado.

De lo anterior puede desprenderse que la explicación a la incorporación del enfoque por competencias dentro de la elaboración de planes y programas de estudios de distintos establecimientos educacionales y, en el caso en particular, en la carrera de Derecho de la UDA, no cobraría total sentido si no se explicitan las finalidades que se le asigna a la configuración del modelo educativo a través de este nuevo paradigma.

No se trata de realizar un juicio de valor al respecto; ya se señaló que el enfoque por competencias resulta ser un tema no pacífico que suma tanto a detractores como defensores. No obstante, es la tendencia en boga por la cual se están reestructurando distintos sistemas educativos, ya sea por su carácter innovador, ya sea por las exigencias de la institucionalidad nacional e internacional.

Entonce, ¿para qué enseñar con un enfoque por competencias? Para dar respuesta a dicha interrogante, necesariamente debe desentrañarse cuáles son las finalidades de la educación. Díaz Barriga (2005: 22) indica que solo puede hablarse de planes y programas de estudios desde el momento en que la educación deja de ser un privilegio de una clase social determinada, asumiendo el Estado el rol de organizador del sistema educativo (siglo XIX), estableciendo su obligatoriedad y gratuidad (siglo XX).

Desde entonces, epistemológicamente se han confrontado distintas visiones que han intentado establecer cuáles deberían ser los fines de la educación. Para Johann Friedrich Herbart, la educación tiene un fin ético: se busca a través de ella la formación del carácter moral y el medio para ello es la psicología; los otros son fines secundarios y subordinados a aquel (Soto y Bernardini, 1982: 64). El fin de la educación, 
para Herbart, es la virtud, que consiste en el acuerdo de la voluntad con las ideas éticas, las cuales se basan en juicios estéticos. Esas ideas éticas son la libertad íntima, la perfección, la benevolencia, el derecho y la equidad, y como hechos dichos con su aceptación se puede modificar la conducta (Luzuriaga, 1971: 204).

Desde la pedagogía activa, John Dewey sostuvo que la educación cumple una doble función: una social y una individual. Por una parte es la suma total de procesos por los cuales una comunidad transmite sus poderes y objetivos con el fin de asegurar su propia existencia y desarrollo, y por otra, es también igual a crecimiento, a una continua reconstrucción de la experiencia. La escuela no es una preparación para la vida, sino la vida misma, depurada; en la escuela el niño tiene que aprender a vivir (Luzuriaga, 1971: 246).

Para Émile Durkheim las finalidades de la educación se vinculan con el individuo y la sociedad (Díaz Barriga, 2005: 24): «Su objeto es suscitar y desarrollar en el niño cierto número de estados físicos, individuales y morales que exigen de él la sociedad política en su conjunto y el medio especial al que particularmente está destinado» (Luzuriaga, 1971: 252).

Freire identifica en la educación un fin liberador frente a una sociedad opresora alienante. Y así podrían invocarse una multiplicidad de teorías que han intentado explicar y definir cuáles son los fines que busca (o debería buscar) la educación.

Pero para Díaz Barriga (2005: 22-23), la visión tecnocrática, vinculada al proceso de industrialización estadounidense, ha ido imponiéndose en los hechos a través de una dimensión pedagógica pragmática.

Para la pedagogía pragmática la educación tiene como fin la calificación de los ciudadanos de acuerdo a las necesidades del mundo del trabajo. Así, «educar para el empleo se convirtió en la finalidad central de la educación» (Díaz Barriga, 2005: 23). La pedagogía pragmática transita a través de una lógica unidimensional: la educación busca desarrollar habilidades técnico-profesionales mediante el aprendizaje de las actitudes que buscan los empleadores (Díaz Barriga, 2005: 23).

En consecuencia, la pedagogía pragmática tiende a la uniformidad, la homogeneización. Al imponerse en la conformación de planes y programas de estudio, la formación del estudiante se estandariza, reduciéndose la dimensión intelectual del docente para transformarse, en la práctica, en un ejecutante y cumplidor de programas.

Esta visión, que pretende una práctica unitaria de docentes y alumnos en relación con los planes y programas de estudio, origina una serie de conflictos dentro de las instituciones educativas. En primer lugar, responde a un intento por despojar al docente de la dimensión intelectual de su trabajo. Se lo considera como un operario en la línea de producción; su tarea consiste en aplicar aquello que unos especialistas han hecho. Esta condición de ejecutante de diversas propuestas implica, en sí misma, elementos de alienación de la práctica docente y del propio maestro como persona. En ocasiones, el docente evidencia esta enajenación cuando manifiesta a sus estudiantes 
que su tarea es «cumplir con el programa», que desconoce el motivo por el que se incorporaron determinados temas, que no sabe qué utilidad o aplicación pueda tener el aprendizaje de determinados contenidos (Díaz Barriga, 2005: 25).

A partir de lo antes señalado, ya se cuenta con algunos elementos de análisis para esbozar alguna respuesta a la finalidad que se persigue de la formación por competencias y si este modelo obedece o no a una visión tecnocrática de la educación.

La formación por competencias, en cuanto concepto complejo, per se no constituiría la proyección de una dimensión pedagógica pragmática. Como señala Tobón (2006: 1), la formación por competencias es un enfoque, no un modelo pedagógico, por tanto, su implementación no debería implicar necesariamente la adopción un esquema educativo uniforme y que tenga como único fin la preparación del estudiante para su calificación para la vida laboral.

En ella se combinan tres elementos: una información, el desarrollo de una habilidad y su puesta en acción en una situación inédita.

La mejor manera de observar una competencia es en la combinación de estos tres aspectos, lo que significa que toda competencia requiere del dominio de una información específica, al mismo tiempo que reclama el desarrollo de una habilidad o, mejor dicho, una serie de habilidades derivada de los procesos de información, pero es en una situación problema, esto es, en una situación real inédita, donde la competencia se puede generar (Díaz Barriga, 2006:20).

De este modo, la formación por competencias tendría por finalidad entregar herramientas para el diseño del currículum de acuerdo a los contextos disciplinares, profesionales, sociales laborales; la implementación de metodologías para el ejercicio de la docencia; la proposición de estrategias dirigidas al desarrollo de destrezas y habilidades del educando, etcétera (Tobón, 2006: 1). Es decir, de modo alguno puede sostenerse que la formación por competencia comprende, por sí misma, la consolidación de la visión tecnocrática de la educación y, para el caso en particular de la carrera de Derecho, «debe descartarse entonces que el nuevo enfoque que se propone oriente sólo la formación a lo laboral, descuidando la formación disciplinar» (Aedo Barrena, 2014: 105).

Una situación distinta viene dada por las políticas públicas y los proyectos educativos de los establecimientos educacionales que fijan sus planes y programas de estudios en el enfoque por competencias. Es en este espacio donde puede imponerse la pedagogía pragmática pues, como lo indica Aedo Barrena (2014: 105), «como la formación por competencias no es un modelo pedagógico, no debe atribuírsele a ella que alguna institución educativa se oriente sólo al mundo laboral, descuidando la excelencia en la formación profesional».

Por lo tanto, que el diseño curricular de la carrera de Derecho de la UDA se estructure con base a la formación por competencias, no implica necesariamente que el fin que se persiga es la especialización del futuro abogado en función de las deman- 
das del mundo del trabajo. El límite se traspasaría desde el instante en que el proyecto educativo de la casa de estudios despoje a la labor formativa de su aspecto intelectual para transitar hacia la uniformidad y a la mera reproducción de contenidos para el cumplimiento de metas y programas.

\section{Conclusiones}

El concepto competencia es polisémico, complejo de definir, además de polémico, puesto que se nutre de distintos elementos sociológicos, culturales e ideológicos, que confrontan a partidarios y detractores. Su uso en educación se remonta a la década de 1960, pero es a partir del último lustro del siglo XX cuando cobra relevancia a propósito del proceso iniciado en Bolonia en el año 1999, por el que se invitó a los establecimientos universitarios europeos a adaptar sus procesos formativos a los desafíos que presenta una sociedad altamente tecnológica y globalizada. Del proceso de Bolonia surgen dos retos principales: rediseñar los planes de estudios de las carreras que se imparten en las casas de estudios superiores enfocando la formación en el desarrollo de las competencias profesionales del estudiantado y, por otra parte, realizar una profunda reflexión crítica acerca de los métodos utilizados por los docentes universitarios en el proceso enseñanza-aprendizaje, en miras a cumplir los objetivos que implica el nuevo paradigma de la formación por competencias.

Si bien es cierto el proceso de Bolonia fue pensado desde y para Europa, los países latinoamericanos no se han mantenido al margen. En el caso de Chile, se ha asumido la tarea de revisar y diseñar los planes de estudio de las carreras universitarias con el fin de adecuarlos al nuevo modelo educativo, en coherencia con lo diagnosticado en el Informe Tuning para América Latina de 2007 y los criterios establecidos por la Comisión Nacional de Acreditación.

En el caso específico de la carrera de Derecho de la UDA, luego de haberse sometido a dos procesos de acreditación en los que fue cuestionado su plan de estudios, el año 2011 experimenta un rediseño curricular que recoge elementos del paradigma de la formación por competencias profesionales, nuevo currículo que, sin perjuicio de la evaluación que deba realizarse respecto de su configuración y los resultados alcanzados por los profesionales formados íntegramente bajo su alero, resulta coherente con el perfil de egreso de la carrera.

Con todo, la implementación de este nuevo enfoque educativo no implicará un cambio sustancial en el proceso formativo si no se asume el desafío de renovar los métodos de enseñanza del derecho, con el objeto de transitar hacia un modelo en el que el estudiante cumpla un rol activo como dueño y constructor de su propio aprendizaje.

En tal sentido, puede concluirse que el método tradicionalmente utilizado para la docencia del derecho es el de la clase magistral, en el que el docente asume el papel 
de un vaciador de contenidos jurídicos, siendo el alumno un mero receptor de los mismos que luego de memorizarlos, deberá replicar al momento de ser evaluado. Tal método de enseñanza, que podemos encasillar en las teorías conductistas del aprendizaje, Paulo Freire lo ha definido como educación bancaria, fiel reflejo, a su juicio, de una sociedad opresora, alienante, a la que se le contrapone la educación liberadora, que construyen en un plano de igualdad educador y educando.

La tarea que debemos asumir es la de lograr incorporar métodos constructivistas en el proceso enseñanza-aprendizaje (role-playing, talleres, investigaciones, debates, análisis de casos, presentaciones orales, etcétera) que permitan plasmar en la práctica la intención de fomentar el pensamiento crítico y complejo de nuestros estudiantes.

No fue la intención de este artículo entregar la receta mágica que contenga la solución a los problemas planteados, sino la de sentar las bases para realizar la necesaria autocrítica, discusión y reflexión. De todos modos, la implementación de nuevas metodologías con una orientación constructivista no tendría sentido si no se tiene claro cuál es la finalidad de la enseñanza del derecho a partir del enfoque por competencias: la formación de especialistas funcionales a las exigencias del mundo del trabajo o, por el contrario, de profesionales con capacidad de reflexión crítica acerca de las dinámicas propias de toda sociedad y de las crisis que se producen como resultado de las complejidades de las relaciones de los seres humanos.

$\mathrm{Al}$ respecto debe tenerse claro que no existe una visión unívoca de las finalidades de la educación, pero, de acuerdo con Díaz Barriga (2005), ha sido la pedagogía pragmática, depositaria de una visión tecnocrática (formar para dar respuesta a las exigencias de la vida laboral), la que en los hechos se ha impuesto en el diseño de planes y programas de estudios a partir del siglo XX.

En consecuencia, podría tenderse a pensar que la formación por competencias es una manifestación más de la pedagogía pragmática; empero, no constituye en sí misma un dogma ni un modelo pedagógico, sino un enfoque en virtud del cual se configura el currículum para el desarrollo de destrezas y habilidades del educando a través de la implementación de métodos pedagógicos que guarden coherencia con el cumplimiento de sus objetivos.

Por consiguiente, que la formación del futuro abogado tienda hacia el modelo pragmático cuyo único eje sea la preparación para el empleo, no depende de la adopción o no de un sistema basado en competencias, sino del espíritu que subyace en el proyecto educativo del establecimiento educacional; de modo tal que, para evitar que el proceso formativo se estandarice, resulta necesario reivindicar la dimensión intelectual del docente y el papel fundamental que cumple el estudiante como coconstructor de su propio aprendizaje. 


\section{Referencias}

Aedo Barrena, Cristián Eduardo (2014). «Formación por competencias y enseñanza del Derecho». Revista Pedagogía Universitaria y Didáctica del Derecho, 1 (1): 104-113. Disponible en http://bit.ly/2NiTCpq.

Alvarado-Herrera, Sindy, Germán González-Sandoval y Yarina Paniagua-Cortés (2018). «Aspectos pedagógicos y curriculares por considerar en el rediseño de un plan de estudios de posgrado con énfasis en docencia universitaria». Revista Electrónica Educare, 22(2): 141-159.

Beneitone, Pablo y otros (2007). Reflexiones y perspectivas de la educación superior en América Latina. Bilbao: Universidad de Deusto. Disponible en http://bit. ly/2FAH8Dh.

Cardinaux, Nancy y María Angélica Palombo (2007). «El pensamiento crítico: llaves, rutas y señuelos». Academia. Revista sobre Enseñanza del Derecho, 5 (10): 117140. Disponible en http://bit.ly/31VgZJa.

CArdozo-Brum, Myriam (1989). «Rediseño curricular de un programa de maestría en Salud Pública. Salud Pública de México». Educación Superior en Salud, 31(3): 407-417.

CNA, Comisión Nacional de Acreditación (2006). Acuerdo de acreditación 308 carrera de Derecho Universidad de Atacama. Santiago. Disponible en https://www. cnachile.cl/res/preg/RES-PREG-00342-01.pdf.

-. (2011). Acuerdo 048/2011. Santiago. Disponible en web: https://www.cnachile.cl/ res/preg/RES-PREG-00342-04.pdf.

Díaz-Posada, Leidy, Sandra Varela-Londoño y Lilian Rodríguez-Burgos (2017). «Inteligencias múltiples e implementación del currículo: avances, tendencias y oportunidades». Revista de Psicodidáctica, 22(1): 69-83.

DíAz BARriga, Ángel (2005). El docente y los programas escolares. Lo institucional y lo didáctico. Barcelona-México: Ediciones Pomares S.A.

-. (2006). «El enfoque de competencias en educación. ¿ ¿na alternativa o un disfraz de cambio?». Perfiles Educativos, 28(111): 7-36.

Elgueta, María Francisca y Eric Palma González (2014). «Una propuesta de clasificación de la clase magistral impartida en la Facultad de Derecho». Revista Chilena de Derecho, 41(3): 907-924.

FreIre, Paulo (2012). Pedagogía del oprimido. Buenos Aires: Siglo XXI.

Ganga, Francisco, Claudia Smith, Paulo Fossatti y Oswaldo Leyva (2017). «Rediseño curricular: Caso de carreras técnicas de una Universidad Estatal Chilena». Revista Espacios, 38(50): 4-13.

Galdeano-Bienzobas, Carlos y Antonio Valiente Barderas (2009). «La enseñanza por competencias». Educación Química, 20 (3): 369-372. DOI: 10.1016/ So187-893X(18)30038-7. 
GiL, José María (2018). «Tensiones productivas del currículo. Dialéctica virtuosa de la educación». Perfiles Educativos, 40(160): 156-173.

Gómez Francisco, Taeli (2014). «Paradigmas emergentes y crisis en la educación en la educación del Derecho: algo más que didácticas». Revista Pedagogía Universitaria y Didáctica del Derecho, 1 (1): 58-71. DOI: 10.5354/0719-5885.2015.35963.

GonZÁLEZ, Julia y Robert Wagenaar (2003). Tuning educational structures in Europe. Informe final fase uno. Bilbao: Universidad de Deusto. Disponible en http:// bit.ly/2 $\mathrm{NcO} 8 \mathrm{fZ}$.

GoÑI, María y Silvia Meseguer (2010). «Diseño curricular centrado en las competencias que debe adquirir el estudiante de grado en Derecho». Formación Universitaria, 3 (2): 37-46. DOI: 10.4067/So718-50062010000200006.

GudiÑo, Doris (2011). «El conductismo y el cognoscitivismo. Dos entramados psicológicos de aprendizaje del siglo XX». Revista Ciencias de la Educación, 21 (38): 297-309. Disponible en http://bit.ly/2xd407n.

GutiérRez-BARBA, Blanca Estela y María de la Luz Valderrábano-Almegua (2017). «Aprendiendo del extra-currículo. Aproximaciones desde el coloquio estudiantil». CADMO 2: 65-78. DOI: 10.3280/CAD2017-002008.

HeRnÁNDEZ-ChACón, Ledy (2017). «Rediseño curricular de la carrera Gestión Social y Desarrollo de la Universidad de Otavalo para su Proceso de Acreditación». Formación Universitaria, 10(6), 3-16.

JimÉNEZ, Iris, Raúl Martelo y José Jaimes (2017). «Dimensiones del empoderamiento digital y currículo para el sector universitario». Formación Universitaria, 10(4): 55-66.

Lazo González, Patricio (2011). «Formación jurídica, competencias y método de enseñanza: premisas». Ius et Praxis, 17 (1): 249-262. DOI: 10.4067/ So718-00122011000100011.

Luzuriaga, Lorenzo (1971). Historia de la educación y de la pedagogía. Buenos Aires: Editorial Losada S.A.

Mesquita, Diana, María Flores y Rui Lima (2018). «Desarrollo del currículo en la enseñanza superior: Desafíos para la docencia universitaria». Revista Iberoamericana de Educación Superior, 9(25): 42-61.

Montero Curiel, Marisa (2010). «El proceso de Bolonia y las nuevas competencias». Tejuelo, (9): 19-37. Disponible en https://dialnet.unirioja.es/descarga/articulo/3719324.pdf.

PAlomo Vélez, Rodrigo y Carolina Riveros Ferrada (2015). «La transformación curricular en Derecho: consideraciones desde la experiencia docente y de gestión académica ». Revista Pedagogía Universitaria y Didáctica del Derecho, 2 (2): 55-75. DOI: $10.5354 / 0719-5885.2015 .38145$.

PÉreZ-Ruiz, Abel (2018). «Práctica docente y currículo: Un marco de análisis construccionista». Revista Electrónica Educare, 22(3): 402-416. 
Pinto Sarmiento, Yenny (2014). «El aprendizaje cooperativo como metodología para la formación por competencias en la carrera de Derecho». Revista Pedagogía Universitaria y Didáctica del Derecho, 1 (2): 69-78. DOI: 10.5354/0719-5885.2015.35982.

Qualitas (2006). Acuerdo de acreditación 474 carrera de Derecho Universidad de Atacama. Santiago. Disponible en http://bit.ly/2RFSqLl.

Rivera Ayala, Luis Alonso (2015). «Cinco competencias genéricas clave en los estudios de Derecho». Revista de Educación y Derecho, 11: 1-19. Disponible en http:// bit.ly/2xilwHa.

Rodríguez-Sosa, Jorge y Carmen Solís-Manrique (2017). «Creencias docentes: lo que se hace en el aula es consecuencia de lo que se piensa». Propósitos y Representaciones, 5 (1): 7-20. DOI: 10.20511/pyr2017.v5n1.155.

Sanromán Aranda, Roberto y Luisa Gabriela Morales Vega (2016). «La educación por competencias en el campo del Derecho». Boletín Mexicano de Derecho Comparado, 49 (146): 179-203. Disponible en http://bit.ly/2xbuinE.

Salas Perea, Ramón (2016). «¿El rediseño curricular sin evaluación curricular es científico?». Educación Médica Superior, 30(2): 1-11.

SLEETER, Christine (2018). «La transformación del currículo en una sociedad diversa: quién y cómo se decide el currículum?». RELIEVE. Revista Electrónica de Investigación y Evaluación Educativa, 24(2): 1-12.

Sото, José y Amalia Bernardini (1982). La educación actual en sus fuentes filosóficas. San José de Costa Rica: Editorial Universidad Estatal a Distancia.

Товón, Sergio (2006). Aspectos básicos de la formación basada en competencias. Talca: Proyecto Mecesup.

-. (2005). Formación basada en competencias. Pensamiento complejo, diseño curricular y didáctica. Bogotá: Ecoe Ediciones. Disponible en http://bit.ly/2LiGrlX.

UDA, Universidad de Atacama (2018). Perfil de Egreso carrera de Derecho. Copiapó: Universidad de Atacama. Disponible en http://bit.ly/2IQr5Ds.

-.(2006). Plan de desarrollo estratégico. Universidad de Atacama 2006-2010. Copiapó: Universidad de Atacama.

Zuvanich Hirmas, Sonia y María Cristina Donetch Ulloa (2016). «Reforma curricular en la carrera de derecho de la Universidad de Magallanes, una experiencia hacia el enfoque en competencias». En Enrique Cáceres Nieto (coordinador), $\mathrm{Pa}$ sos hacia una revolución en la enseñanza del derecho en el sistema romano-germánico. Tomo 3. México: Universidad Nacional Autónoma de México. Disponible en http://bit.ly/2KLS7hJ.

\section{Sobre el autor}

Tomás Eduardo Garay Pérez es abogado y académico de la Facultad de Derecho de la Universidad de Atacama. Cursa el programa de Magíster en Educación mención Cu- 
rrículum y Evaluación de la Facultad de Humanidades y Educación de la Universidad de Atacama. Su correo electrónico es tomasgarayperez@gmail.com. (D) https://orcid. org/0000-0003-2113-7949. 
La Revista Pedagogía Universitaria y Didáctica del Derecho (RPUDD) es una publicación científica semestral que contribuye a la reflexión multidisciplinaria sobre pedagogía universitaria y didáctica del derecho, para la formación y consolidación de esta área de investigación; así como a la difusión de prácticas innovadoras en la enseñanza-aprendizaje del derecho considerando el contexto nacional e internacional. Es una publicación electrónica internacional con una codirección entre Brasil y Chile.

\author{
DIRECTORA \\ María Francisca Elgueta Rozas \\ Universidad de Chile \\ DIRECTOR \\ Renato Duro Dias \\ Universidad Federal de Rio Grande, Brasil \\ SITIO WEB \\ pedagogiaderecho.uchile.cl \\ CORREO ELECTRÓNICO \\ rpedagogia@derecho.uchile.cl \\ LICENCIA DE ESTE ARTÍCULO
}

Creative Commons Atribución Compartir Igual 4.o Internacional

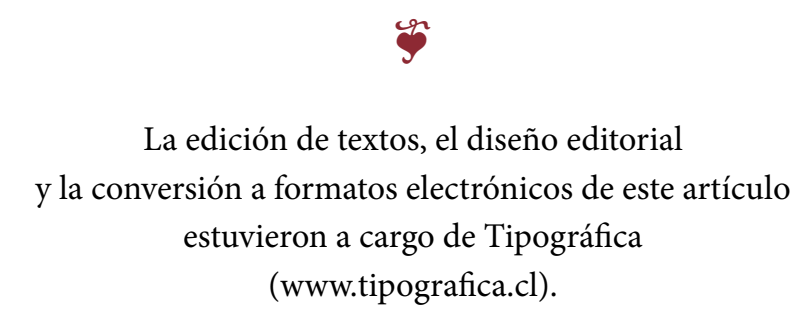

